\title{
e-Nelayan the Fishery Marketplace App
}

\author{
MOHAMMAD NAZRUL MORNIE, NURFAUZA JALI*, KARTINAH ZEN, \\ SURIATI KHARTINI JALI
}

\author{
Faculty of Computer Science and Information Technology, Universiti Malaysia Sarawak, 94300 Kota \\ Samarahan, Sarawak, Malaysia. \\ *Corresponding authors: jnurfauza@unimas.my
}

\begin{abstract}
Smartphones have become an essential device that not only acts as a communication media, but it is also able to assist its user to do multiple tasks. A fisherman is an example of a community member that uses a smartphone. If a smartphone is fully utilised, it can be a huge help for the fishermen to sell their catch and fishery products. However, there is no proper medium, such as an mobile application, for this group of people to sell their catch. Hence, the e-Nelayan Marketplace App is introduced. This app enables the fishermen mainly in Kota Samarahan to sell their catch and other fishery products more effectively. The functionalities of this app include the ability to advertise the catch and let customers and fishmongers know the type of fish being sold. In addition, an interactive graphical user interface was designed to display the output of each functional module. In order to evaluate the user acceptance towards the app, several tests were conducted, such as the performance, portability, compatibility, and usability testing. With the development of this project, it is hoped that the application will benefit not only fishermen but also customers and fishmongers.
\end{abstract}

Keywords: Fishermen, Kota Samarahan, Marketplace mobile application, Mobile Application, Marketplace

Copyright: This is an open access article distributed under the terms of the CC-BY-NC-SA (Creative Commons Attribution-NonCommercial-ShareAlike 4.0 International License) which permits unrestricted use, distribution, and reproduction in any medium, for non-commercial purposes, provided the original work of the author(s) is properly cited.

\section{INTRODUCTION}

The Marketplace App for the e-Nelayan project is conducted to help the fishermen, mainly in Kota Samarahan with their fish trading activities. The usage of smartphones is now in the mainstream; however, there is no available mobile application that can be used by the fishermen, specifically in Kota Samarahan, that can aid such fish trading activities. Thus, the presence of a mobile marketplace application can be an excellent platform for the fishermen to sell their fish to buyers in Kota Samarahan. Targeted groups of users for this mobile application are the fishermen in Kota Samarahan, customers and fishmongers. With regard to the targeted groups, several essential features would be present in this mobile application.

The outcome of this project is a mobile application that can help fishermen to improve their business. This mobile application acts as a marketplace for the user community of fishermen, sellers and costumers. The first group, which is the fishermen, will be able to post their catch using the application together with information about the said catch. They can make advertisements to target buyers. The fishermen can also set the price of the fish differently for different types of users. The sellers can provide two types of options to purchase the fish: selfpick-up or cash upon delivery. Finally, customers can post their demand for specific types of fish, which can then be commented on by sellers or the fishermen themselves.

\section{A. Problem Statement}

Mobile apps in fisheries are becoming common in developed countries. However, it is still unexplored in Malaysia, which becomes a limiting factor in the evolution of the fisheries industry, especially in Kota Samarahan. The fisheries industry in Kota Samarahan only practises the conventional method of supplying fish to the customer from fishermen. Apart from that, there is also a lack of a platform, such as mobile applications, to allow fishermen to sell their catch in an easy and quick way. 


\section{B. Objectives and Scope}

The goals of the project were generally to support fishermen in Kota Samarahan to increase their sales and improve their revenue. In order to accomplish this, three goals must be achieved:

i. $\quad$ To investigate the current manual system of fish trading activities.

ii. To develop a mobile application with embedded features that could help the fishermen to calculate their income easily.

iii. To support the fishermen to market their catch without the need for a middle person.

This project is aimed to develop a fully functional mobile application for the fish marketplace that can be used by the local people in Kota Samarahan, primarily fishermen, fishmongers, and customers, to perform fish trading transactions. The scope of this project is as follows:

i. This mobile application will be accessible using the user's Android devices only.

ii. This mobile application will not be available on any personal computers with an operating system such as Windows and macOS.

iii. The target users for this mobile application are the fishermen, fishmongers, and customers in Kota Samarahan.

iv. This mobile application acts as a marketplace for user's fish trade in Kota Samarahan.

\section{LITERATURE REVIEW}

\section{A. Evaluation of the Existing System}

There are three existing systems that have similar functions or features as the proposed application. The existing systems are Fish.me (Inc, 2018), OneFarm (Plt, 2017), and Farmers e-market (Limited, 2017). These systems were reviewed to obtain their strengths and weaknesses in order to produce the best solution for the proposed application. Table 1 summarises the comparison between the existing systems and the proposed application.

Table 1. Comparison between three existing systems and proposed application

\begin{tabular}{|c|c|c|c|c|}
\hline Evaluation Criteria & Fish.me & OneFarm & $\begin{array}{l}\text { Farmers e- } \\
\text { market }\end{array}$ & $\begin{array}{l}\text { Marketplace App for e- } \\
\text { Nelayan Kota Samarahan } \\
\end{array}$ \\
\hline Login system & $\sqrt{ }$ & $\sqrt{ }$ & $\sqrt{ }$ & $\sqrt{ }$ \\
\hline Categorisation of products & $\mathrm{X}$ & $\sqrt{ }$ & $\sqrt{ }$ & $\sqrt{ }$ \\
\hline Purchasing method & $\begin{array}{l}\text { Cash upon } \\
\text { delivery only }\end{array}$ & $\begin{array}{l}\text { Depending on } \\
\text { the seller }\end{array}$ & Self-pickup & $\begin{array}{l}\text { Self-pickup \& cash upon } \\
\text { delivery }\end{array}$ \\
\hline Search features & $\mathrm{X}$ & $\mathrm{X}$ & $\sqrt{ }$ & $\sqrt{ }$ \\
\hline Type of user & $\begin{array}{l}\text { Customer \& } \\
\text { fishermen }\end{array}$ & $\begin{array}{l}\text { Hybrid-type } \\
\text { user }\end{array}$ & $\begin{array}{l}\text { Hybrid-type } \\
\text { user }\end{array}$ & $\begin{array}{l}\text { Customer, fisherman, \& } \\
\text { seller }\end{array}$ \\
\hline $\begin{array}{l}\text { Ability to view the same } \\
\text { seller's product }\end{array}$ & $\sqrt{ }$ & $\mathrm{X}$ & $\mathrm{X}$ & $\sqrt{ }$ \\
\hline Account Management & $\sqrt{ }$ & $\sqrt{ }$ & $\sqrt{ }$ & $\sqrt{ }$ \\
\hline Cart feature & $\sqrt{ }$ & $\mathrm{X}$ & $\mathrm{X}$ & $\sqrt{ }$ \\
\hline User interaction & $\mathrm{X}$ & $\sqrt{ }$ & $\mathrm{X}$ & $\sqrt{ }$ \\
\hline Shareability & $\mathrm{X}$ & $X$ & $\sqrt{ }$ & $\sqrt{ }$ \\
\hline
\end{tabular}

The strengths of the existing systems will be reviewed and adopted; meanwhile, the deficiency of the existing systems would be analysed and enhancements designed in the proposed application. Firstly, the proposed 
application will be included with a login system that is able to differentiate different types of users. There will be three types of users for this app which are fishermen, fishmonger, and customer. The proposed application will also include the categorisation of products. Next, the proposed application allows fishermen or other sellers flexibility in determining payment choices. Fishermen may choose whether to use cash upon delivery, self-pickup, or both. Apart from this, the app also provides a search function that will make it easy for users to find products. The proposed application's user interface would be rendered as simple as possible, thus maintaining its usability. The choice of colour, type, and size of font and placement of images are some of the essential aspects to take into consideration. It will also allow the user to manage their accounts, such as changing phone numbers or addresses.

Furthermore, users will also be able to add the products they want to buy to the cart while continuing to shop for other products. The proposed application will also be built with a function where customers can post their demands so that fishermen or other sellers can comment on the said posts. The seller also can write a post to notify that they have added new products.

\section{MATERIAL \& METHODOLOGY}

The methodology that was chosen for this project is Extreme Programming (XP). Extreme Programming is one of the methodologies available in the Agile method. XP is a software development methodology that allows the improvement of software quality to fully satisfy the needs of the clients (Powell-Morse, 2017). By using the XP method, the quality of this mobile application can be adjusted periodically according to the user's satisfaction level (Shafiq \& Minhas, 2014). Planning, designing, coding, testing, and listening are the five phases of the Extreme Programming (XP) software life cycle (Sergeev, 2016). Besides, the feature of the mobile app can be frequently updated since there is a specified timeframe for each software cycle to meet the requirements of the targeted users. As the cycle progresses from one iteration to another, the quality of the mobile application is increased. There are five main principles requiring consideration when utilising the XP technique which consists of simplicity, contact, suggestions, respect, and bravery. These principles must be followed to maintain the efficacy of the development process.

This section mainly covers the software methodology processes from the analysis and design of requirements up to the testing of the e-Nelayan Marketplace app. Requirements needed for the application were listed and discussed in detail, while the user interface, database, and application's architecture were properly designed.

There were several tasks that have been done for each phase in the Extreme Programming (XP) methodology. Each phase contained a unique list of tasks. Table 2 summarises the tasks that have been completed for each of the methodology's phases.

\section{A. User Requirement}

For the user requirements, interviews and questionnaires were used to obtain user's views and opinions on the proposed application. Semi-structured interview was used to gain feedback from the fishermen. The questionnaires were disseminated to the customers and fishmongers.

The interviews were conducted in Kampung Muhibbah, Kota Samarahan. The total number of active fishermen in Kampung Muhibbah was around 13 people, where a total of five respondents had been interviewed to obtain their opinions and suggestions on the proposed application. Based on the interview outcomes, most of the respondents agreed that the proposed application would benefit them. Table 3 depicts the respondents' views of the proposed application. 
Table 2. Summary of tasks for each phase in the XP methodology.

\begin{tabular}{|c|c|}
\hline Phase & Tasks \\
\hline Planning & $\begin{array}{l}\text { 1. Interviewing the fishermen, } \text { LKIM }^{*} \text { officers and fish dealers. } \\
\text { 2. Distribute the questionnaires to fish customers and fishmonger in Kota Samarahan. } \\
\text { 3. Estimating and drafting the project completion schedule. } \\
\text { 4. Listing the requirements for the proposed application. }\end{array}$ \\
\hline Design & $\begin{array}{l}\text { 1. Reviewing three existing systems that have similar functions as proposed application. } \\
\text { 2. Draw different types of UML diagram that serves a specific purpose for the proposed } \\
\text { application. }\end{array}$ \\
\hline Coding & $\begin{array}{l}\text { 1. Coding of features to be made accessible in the proposed application based on the } \\
\text { requirements and design from planning and design phases. } \\
\text { 2. Divide features of the proposed application into a smaller part. } \\
\text { 3. Codes each part of divided features of the proposed application. } \\
\text { 4. Revised the completed codes after tested with users. }\end{array}$ \\
\hline Testing & $\begin{array}{l}\text { 1. Test each part of the completed code with the target users. } \\
\text { 2. Record the results of the tests to improve each part of the codes }\end{array}$ \\
\hline Listening & $\begin{array}{l}\text { 1. Record feedback from the users to revise the requirements of the proposed application. } \\
\text { 2. Repeat phase design, coding, testing, and listening for next iteration if any changes should } \\
\text { be made. If no changes, the iteration ends at this phase. }\end{array}$ \\
\hline \multicolumn{2}{|c|}{$\begin{array}{l}\text { * Lembaga Kemajuan Ikan Malaysia Negeri Sarawak or known as Fisheries Development Authority of Malaysia } \\
\text { Table 3. Fishermen's opinion on how the proposed application would help. }\end{array}$} \\
\hline Respondents & How the proposed application will help \\
\hline 1 & $\begin{array}{l}\text { Will make it much easier to sell the fish directly to the customer and at the same time able to } \\
\text { increase income since more people are using mobile devices }\end{array}$ \\
\hline 2 & Easy to sell fish because sometimes it took a long time to wait for dealers to come \\
\hline 3 & Can put a better price rather than a lower price from the fish dealers \\
\hline 4 & Easier to understand the fish market price \\
\hline 5 & Able to understand the needs and demands of the consumer \\
\hline
\end{tabular}

For the fishmongers, a total of 21 respondents responded to the questionnaire. Questionnaires were administered to the fishmonger in Kota Samarahan mainly in Market Basah Bandar Riyal and fish market near Asajaya. Out of 21 respondents, 13 had their fish supplied directly from fishermen. This showed that most of the fishmongers get their fish stock from the fishermen. It also implies that fishermen were the most important parties in the supply of fish stock to the fishmongers.

For the customers, the questionnaires were disseminated randomly to the residents in Kota Samarahan. 36 respondents had responded whereby $62 \%$ of the customers bought fish directly from the fishermen. This is because they believe that the price is much lower than the one sold by the fishmonger. By using this mobile application, it will be much easier for these customers to get fish directly from the fishermen because the fishermen are the main users of this application. The fishermen can directly advertise their catch while the customer will be able directly buy the fishermen's catch using this mobile application. This will help to satisfy the customer's preference while at the same time able to clear the fishermen's catch in a faster manner. 


\section{B. Application Design}

Among the other steps, the design phase is the most critical since a device blueprint enables developers to avoid all misunderstandings about the app including users. In this section, two types of design which are the module design and user interface design were used to design the features and functionalities.

In module design, overall modules of the proposed application were designed using a use case diagram visualised in Figure 1. Each module has different actors associated with it. For example, the login module serves customers and sellers, which is the generalised actor for fishermen and fishmongers.

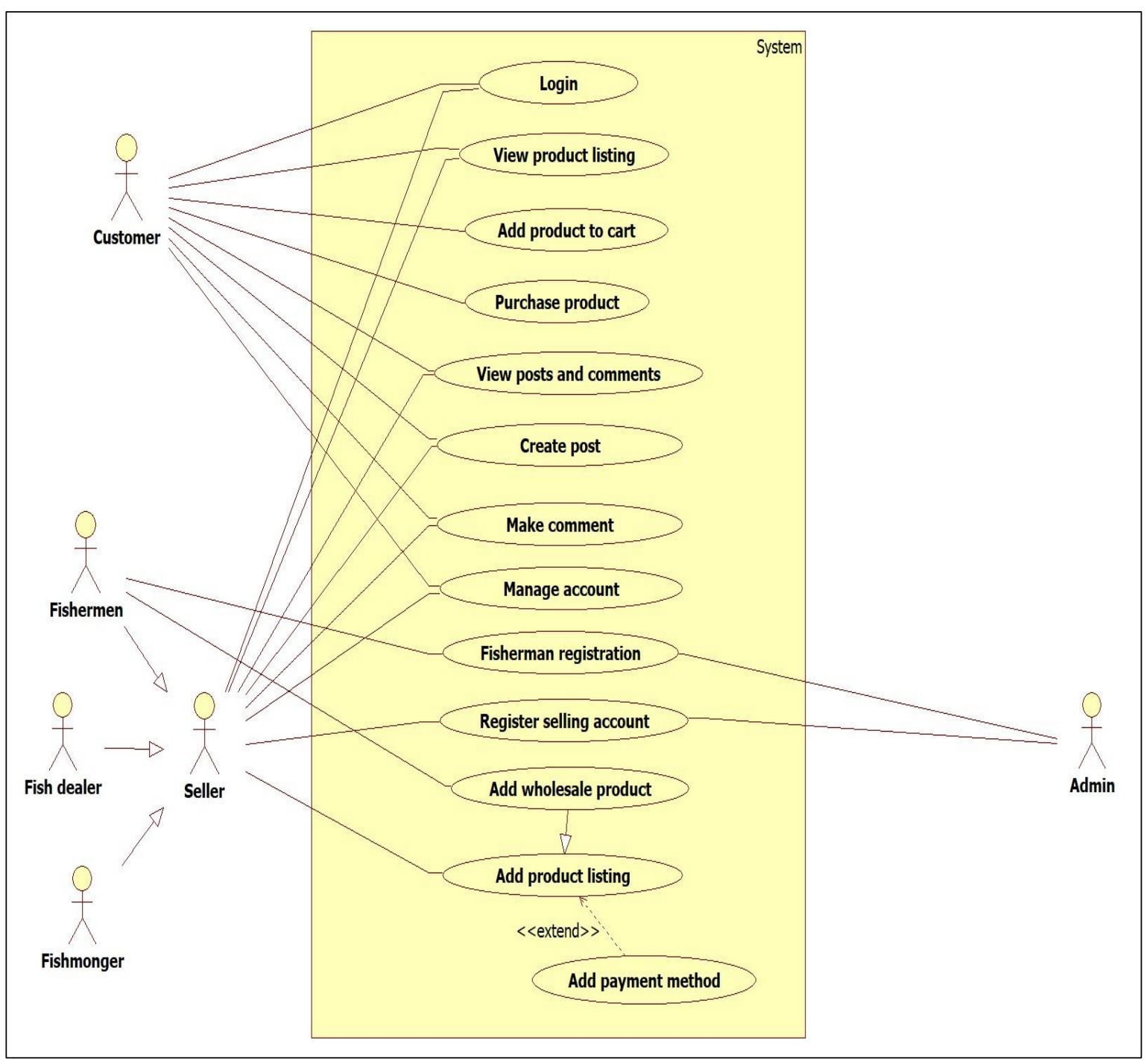

Figure 1. The use case diagram of Marketplace Apps for e-Nelayan Kota Samarahan.

Meanwhile for the user interface design, Adobe XD was used to create the wireframe of proposed application. It was created to visualise user interface of the proposed application. The user interface design for homepage of the proposed application is displayed as in Figure 2.

\section{Implementation}

This section focuses on the implementation of the proposed application. First of all, the development configuration will be discussed in detail. It also includes the details of the tools used and how they play crucial roles in the development phase. In addition, the roles of each type of user utilising this application are also addressed. Finally, this section will also discuss the developed prototype of the application. 


\section{i. Installation and Configuration of System's Components}

In order to successfully develop the proposed application, several tools and system components were installed. The tools and components are crucial to ensure that the development process can be conducted and that the required features for the application can be obtained. Android Studio, an integrated development environment, is the most important tool utilised in this project that was used to write the codes of the application. It was used to apply the designs and functions of the proposed application.

The database system that has been chosen for the app was Firebase. More specifically, the components used in this application were Firebase Realtime Database, Firebase Storage, and Firebase Authentication. Firebase Realtime Database was used to store any type of data inside the application such as the products and user account. The data stored inside the Firebase Realtime Database is in JSON format. The Firebase Storage was used to store images used in the application, such as the user profile image and product image. Firebase Authentication was used for storing user credentials depending on the type of authentication chosen. For this application, the authentication method chosen was email and password.

\section{ii. Introduction to Role-Based Access}

There are various roles for each type of app user. Table 4 represents the roles for each type of user in more detail.

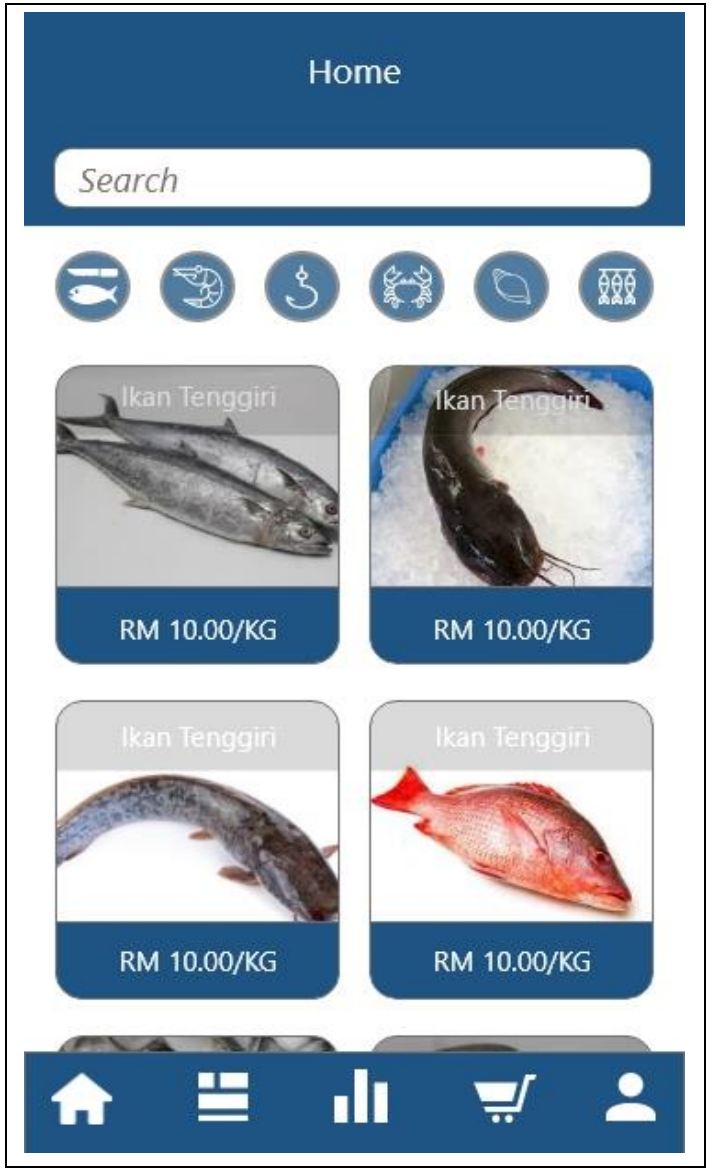

Figure 2. Wireframe for the homepage of Marketplace for e-Nelayan Kota Samarahan.

Table 4. Summary of roles for each type of user in Marketplace App for e-Nelayan.

\begin{tabular}{|c|c|c|c|c|}
\hline Tasks & Admin & Customer & Seller & Fishermen \\
\hline Approve seller account application & $\checkmark$ & $x$ & X & $x$ \\
\hline Approve fisherman account application & $\checkmark$ & $x$ & $x$ & $x$ \\
\hline Login into the application & $x$ & $\checkmark$ & $\checkmark$ & $\checkmark$ \\
\hline View product listing & $x$ & $\checkmark$ & $\checkmark$ & $\checkmark$ \\
\hline Add product to cart & $x$ & $\checkmark$ & $\checkmark$ & $\checkmark$ \\
\hline View cart items & $x$ & $\checkmark$ & $\checkmark$ & $\checkmark$ \\
\hline Purchase product & $x$ & $\checkmark$ & $\checkmark$ & $\checkmark$ \\
\hline View posts and comments & $x$ & $\checkmark$ & $\checkmark$ & $\vee$ \\
\hline Creating posts & $x$ & $\checkmark$ & $\checkmark$ & $\checkmark$ \\
\hline Making posts & $x$ & $\checkmark$ & $\checkmark$ & $\checkmark$ \\
\hline Register selling account & $x$ & $\checkmark$ & $x$ & $\mathrm{x}$ \\
\hline Register fishermen account & $x$ & $\checkmark$ & X & $x$ \\
\hline Add product listing & $x$ & $x$ & $\checkmark$ & $\checkmark$ \\
\hline View customer purchase list & $x$ & $\mathrm{x}$ & $\checkmark$ & $\checkmark$ \\
\hline Add wholesale product & $x$ & $x$ & $x$ & $\checkmark$ \\
\hline
\end{tabular}




\section{iii. Modules for Marketplace App for e-Nelayan Kota Samarahan}

Every module that has been designed was implemented into a working prototype. The modules were Start Page Module, Login Module, Register Module, Cart Module, Product Module and Account Module. For example, in the Product Module, the product that has been listed by the fisherman or seller will appear at the homepage of the application. This page will be displayed to all types of users except the admin since admin will have a separate application. The homepage is integrated with a search function to make it easier for customers or the sellers to search for their products. The list of products is displayed in a grid view which has been chosen by target users during the needs analysis process of the application. In the homepage, the users will only be able to view the product's name, image and price per kilogram. In order to view the details of the products, the users need to click on a selected item and the details of the products will be displayed, together with the seller information. Figure 3 to Figure 6 illustrate the developed features of the Marketplace App for e-Nelayan.

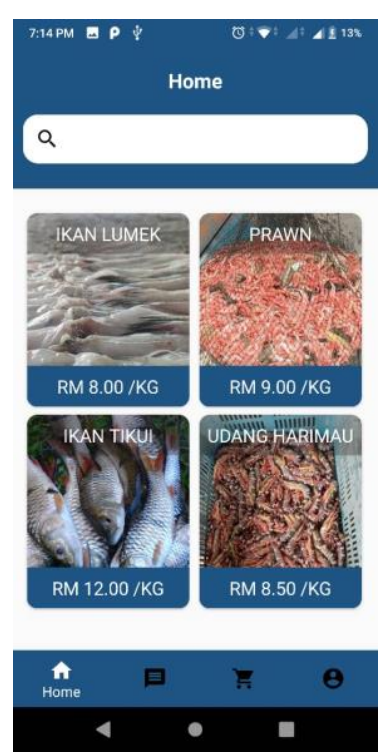

Figure 3. Home page of Marketplace App for e-Nelayan

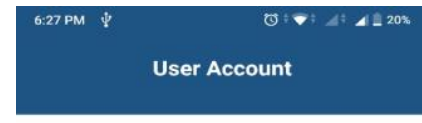

Manage Account

My Post

My Purchase List

Register as Seller

I am a Fisherman

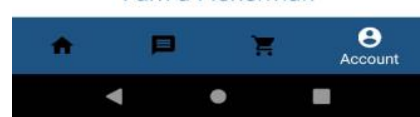

Figure 5. Account page for customers

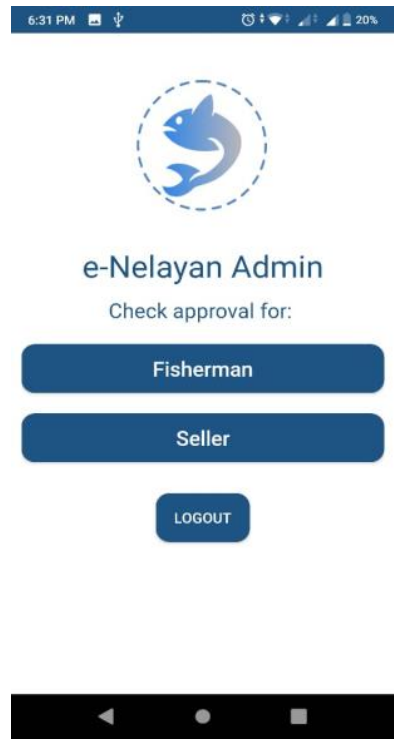

Figure 4. Home page of eNelayan Admin application

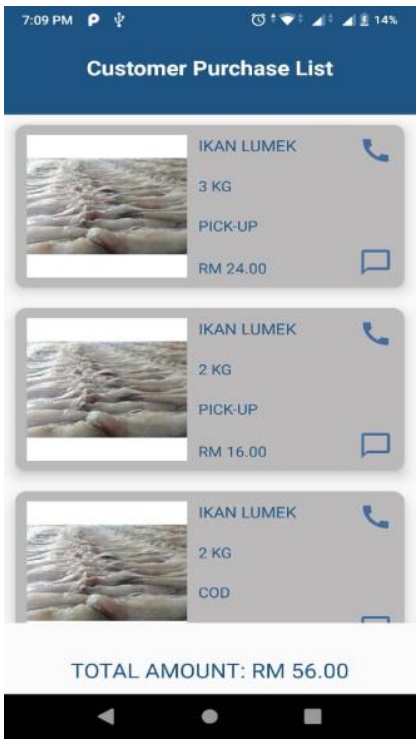

Figure 6. Customer purchase list page 


\section{Testing}

This section will discuss the testing conducted for Marketplace App for e-Nelayan. Two types of tests were conducted which are functional test and non-functional test. The functional testing was done to ensure that the application is working as expected before proceeding to the non-functional testing. Non-functional testing on the other hand is the test that is not related to the application's function and was conducted to obtain user's feedback and level of satisfaction for the application.

Functional testing was conducted to test whether the application behaves as it should. This type of testing is conducted by the developer without the need for participation from target users. Functional testing is very important because it will test whether the functions of the application are ready to be tested. There will be two types of functional testing conducted which are unit testing and system testing.

Unit testing was conducted to test each module or unit of the application. The goal of this test was to ensure that each module of the application is working as expected. Every module was tested according to the test plan. This test was conducted on both the main application as well as the admin application. Every tested unit shows the expected result.

System testing was conducted to test the overall functions of the application. This test was performed to ensure that the developed app satisfies all requirements. Based on the system testing findings, the application performs well and is ready to be tested with targeted users.

Non-functional testing is a type of testing that is performed to test the non-functional components of the application. There were four types of non-functional testing conducted in this project which are performance testing, portability testing, compatibility testing, and usability testing. Due to the current pandemic situation, the usability testing was conducted with users around Matu and Kampung Penipah in Pulau Bruit instead of users in Kota Samarahan. The reason is that the researcher is from Pulau Bruit and during the lockdown period, the state government imposed restrict inter-district movement in Sarawak. A total of 40 respondents participated in this test where 20 of them are customers, ten are fishermen and another ten are fishmongers. Tables 5 until 10 display the results of the non-functional testing.

Table 5. Test case for performance testing. Objective: To test the overall performance of Marketplace App for e-Nelayan

\begin{tabular}{lllll}
\hline Test ID & Test Case & Expected Result & Actual Result & $\begin{array}{l}\text { Pass } \\
\text { /Fail }\end{array}$ \\
\hline \multirow{3}{*}{ PT1 } & $\begin{array}{l}\text { The application must be able } \\
\text { to respond to a user action in } \\
\text { less than 30 seconds for any } \\
\text { type of action }\end{array}$ & $\begin{array}{l}\text { The application should be } \\
\text { able to respond to user } \\
\text { action below 30 seconds }\end{array}$ & $\begin{array}{l}\text { The application was able to respond } \\
\text { within 30 seconds but this depended } \\
\text { on the user's internet connection } \\
\text { speed }\end{array}$ & Pass \\
\hline
\end{tabular}

Table 6. Test case for portability testing. Objective: To test the portability of Marketplace App for e-Nelayan

\begin{tabular}{lllll}
\hline Test ID & Test Case & Expected Result & Actual Result & $\begin{array}{l}\text { Pass / } \\
\text { Fail }\end{array}$ \\
\hline PP1 & $\begin{array}{l}\text { The application is portable } \\
\text { and installed on Android } \\
\text { devices }\end{array}$ & $\begin{array}{l}\text { The application should be } \\
\text { able to be installed on any } \\
\text { portable Android devices }\end{array}$ & $\begin{array}{l}\text { The application can be installed on } \\
\text { any portable Android devices }\end{array}$ & Pass \\
\hline
\end{tabular}

Table 7. Test case for compatibility testing. Objective: To test the compatibility of Marketplace App for e-Nelayan

\begin{tabular}{lllll}
\hline Test ID & Test Case & Expected Result & Actual Result & $\begin{array}{l}\text { Pass / } \\
\text { Fail }\end{array}$ \\
\hline \multirow{2}{*}{ CT1 } & $\begin{array}{l}\text { The application is only } \\
\text { compatible with Android } \\
\text { version } 4.4 \text { and above }\end{array}$ & $\begin{array}{l}\text { The application should be } \\
\text { compatible with any } \\
\text { Android devices with } \\
\text { version 4.4 and above }\end{array}$ & $\begin{array}{l}\text { The application is compatible with } \\
\text { any Android devices with version } 4.4 \\
\text { and above }\end{array}$ & Pass \\
\hline
\end{tabular}


Table 8. Results of usability testing for Marketplace App for e-Nelayan user interface.

\begin{tabular}{lllllll}
\hline No & Test elements & $\mathbf{1}$ & $\mathbf{2}$ & $\mathbf{3}$ & $\mathbf{4}$ & $\mathbf{5}$ \\
\hline 1 & I think that it is very easy to understand and use this mobile application & 0 & 0 & 3 & 0 & 37 \\
2 & I think that the size of the font used for this application is suitable & 0 & 0 & 0 & 0 & 40 \\
3 & I think the color chosen for this application is suitable and attractive & 0 & 0 & 1 & 6 & 33 \\
4 & I found that the products are displayed in a very pleasing and organised way & 0 & 0 & 0 & 0 & 40 \\
5 & I found that the post and comments page is very well organised & 0 & 0 & 0 & 1 & 39 \\
6 & I found out that the account section is very understandable & 0 & 0 & 0 & 0 & 40 \\
\hline
\end{tabular}

Note. $1=$ Very unsatisfied, $5=$ Very satisfied

Table 9. Results for user overall evaluation of Marketplace App for e-Nelayan.

\begin{tabular}{lllllll}
\hline No & Test sample & $\mathbf{1}$ & $\mathbf{2}$ & $\mathbf{3}$ & $\mathbf{4}$ & $\mathbf{5}$ \\
\hline 1 & How satisfied are you with the experience of using this application? & 0 & 0 & 1 & 2 & 34 \\
\hline
\end{tabular}

Note. 1 = Very unsatisfied, $5=$ Very satisfied

Table 10. Suggestions and opinions about Marketplace App for e-Nelayan.

\begin{tabular}{ll}
\hline No & Suggestions \\
\hline 1 & Add the option to switch to the Malay language \\
2 & Add online payment method \\
3 & Add promotion \\
4 & Add iOS version of the application \\
\hline
\end{tabular}

\section{CONCLUSION AND FUTURE WORK}

This paper described our work in developing an Android mobile application to help the fishermen to sell their catch and fisheries products called Marketplace App for e-Nelayan. The mobile application has met all the required features and functions as well as achieved all the project objectives. Thus, the application is now ready to be used as a platform for fish trading activities for targeted users which are fishmongers, customers, and fishermen in Kota Samarahan. However, the application can be further developed to increase its usability and user acceptance.

The limitations of Marketplace App for e-Nelayan can be solved in the future to increase its usability and user acceptance. For future enhancements, Marketplace App for e-Nelayan should be added with the Malay language option. This is because some targeted users are unfamiliar with English. Furthermore, the application should be compatible with either Android and iOS platforms, and should be published into Google Play Store and Apple App Store in the future so that the sharing function can be enabled. This will support a better performance of the application while allowing the fishermen to share their products more easily.

\section{ACKNOWLEDGEMENTS}

We would like to acknowledge and thank everyone involved in this project, especially the Faculty of Computer Science and Information Technology, UNIMAS and Universiti Malaysia Sarawak. We would also like to express our gratitude to the respondents who sacrificed their time by helping us during the interview session and helped to complete the questionnaire. 


\section{REFERENCES}

Limited, V. I. (2017). Farmers e market [Mobile Application Software]. https://play.google.com/store/apps/ details?id=com.vcodeinfosystems.vcode.farmersclub\&hl=en

Inc, F. T. (2018). Fish.me - Fresh Seafood. Same day delivery [Mobile Application Software]. https://play.google. $\mathrm{com} /$ store/apps/details?id=me.fish.fishbuyer\&hl=en

Plt, A. (2017). OneFarm [Mobile Application Software]. https://play.google.com/store/apps/details?id=com. veonic.onefarm\&hl=en

Powell-Morse, A. (2017). Extreme Programming: What Is It And How Do You Use It? Retrieved from https://airbrake.io/blog/sdlc/extreme-programming

Sergeev, A. (2016). Life Cycle of Extreme Programming. Retrieved November 27, 2019, from https://hygger.io /blog/life-cycle-of-extreme-programming/

Shafiq, S., \& Minhas, N. M. (2014). Integrating Formal Methods in XP-A Conceptual Solution. Journal of Software Engineering and Applications, 07(04), 299-310. https://doi.org/10.4236/jsea.2014.74029 